\title{
Renal Sinus
}

National Cancer Institute

\section{Source}

National Cancer Institute. Renal Sinus. NCI Thesaurus. Code C162219.

A cavity in the kidney containing the pelvicalyceal system, blood vessels, nerves and fat. It communicates with the perinephric space. 